\title{
TRIGO: AVALIAÇÃO TECNOLÓGICA DE NOVAS LINHAGENS (1)
}

\author{
CELINA RAQUEL DE OLIVEIRA CAMARGO $(2,4)$ \\ e CARLOS EDUARDO DE OLIVEIRA CAMARGO $(3,4)$
}

\section{RESUMO}

Avaliou-se a qualidade tecnológica das linhagens de trigo IAC-22, IAC-31, IAC-37, IAC-41, IAC-46, IAC-57 e IAC-60, obtidas pelo programa de melhoramento do Instituto Agronômico, tomando como controle uma amostra de trigo norte-americano e amostras dos cultivares Alondra-S-46 e IAC-18, comerciais no Estado de São Paulo. Os maiores teores de proteína foram encontrados no 'IAC-22' e nas linhagens IAC-37 e IAC-41, superiores àqueles das farinhas de trigo importado, Alondra-S-46 e IAC-18. Todas as farinhas de trigo apresentaram viscosidade máxima superior a 1.000 unidades amilogrắficas, indicando a ausência da enzima alfa-amilase. As farinhas de trigo importado e das linhagens IAC-31, |AC-41 e |AC-57 apresentaram características farinográficas típicas de farinha de força média a forte e IAC18 e IAC-60, de farinha média a fraca. Os extensigramas mostraram que as linhagens $|A C-41| A C-31,, \mid A C-57$ e |AC-46 apresentaram glúten com características viscoelásticas adequadas para a produção de pão. Pelo teste de panificaçăo, concluiu-se que as linhagens IAC-31 e IAC-41 produziram pão de qualidade "muito boa", semelhante à da farinha de trigo importado;

(1) Trabalho apresentado na XIV Reuniāo Nacional de Pesquisa de Trigo, Londrina (PR), julho de 1986. Recebido para publicaçāo em 20 de agosto de 1986.

(2) Departamento de Tecnologia de Alimentos, Faculdade de Engenharia de Alimentos, Universidade Estadual de Campinas (UNICAMP), 13100 Campinas (SP).

(3) Seção de Arroz e Cereais de Inverno, Instituto Agronômico (IAC), Caixa Postall 28, 13001 Campinas (SP).

(4) Com bolsa de suplementaçăo do CNPq. 
IAC-57, IAC-37 e IAC-60, pão de qualidade "boa" e similar à do 'Alondra-S-46; as linhagens IAC-46 e IAC-22 tiveram o pior comportamento em relação à qualidade de pão, "regular", semelhante à do "IAC-18'.

Termos de indexação: trigo, cultivares, novas linhagens; testes químicos, reológıcos, de panificação; proteina, teores; viscosidade máxima, características farinográficas.

\section{INTRODUÇÃO}

Na década de 1960, no Estado de São Paulo, plantaram-se anualmente cerca de 20.000 ha com trigo. Em 1984, com o crescente estímulo do Governo Federal, além da intensificação do programa de pesquisa com esse cereal pelo Instituto Agronômico, visando à obtenção de novos cultivares (FELíclO et al., 1983, 1985), aquela área foi ampliada para 140.000 ha (PROGNÓSTICO 84/85, 1984).

A demanda por novos cultivares adaptados às regiōes produtoras intensificou-se, procurando-se não só aqueles com tolerância à toxicidade de alumínio (CAMARGO \& OLIVEIRA, 1981), mas também os cultivares de porte semi-anão e de características como a resistência às ferrugens e ao acamamento, ciclo precoce, alta produtividade (CAMARGO, 1972; CAMARGO et al., 1985a, b).

Além do melhoramento genético do trigo visando às características agronômicas, todavia, é necessário avaliar a qualidade tecnológica da sua farinha, - que possibilita conhecer as linhagens de potencial para serem lançadas e recomendadas aos triticultores.

O presente trabalho teve por objetivo avaliar tecnologicamente a qualidade de sete novos cultivares originários do programa de melhoramento genético do trigo do Instituto Agronômico, usando-se como controle dois cultivares de trigo comercial e uma amostra de trigo importado norte-americano.

\section{MATERIAL E MÉTODOS}

\subsection{Linhagens estudadas}

Foi avaliada tecnologicamente a qualidade das seguintes linhagens:

IAC-31 - Selecionada a partir do híbrido 127 (Bajio-67 x IAC-5), apresenta ciclo da emergência à maturação de 105 dias, altura das plantas de $97 \mathrm{~cm}$, resistência a três raças de ferrugem do colmo, boa produtividade e moderada tolerância ao $\mathrm{Al}^{3+}$.

IAC-41 - Oriunda da seleção de progênies do hibrido 392 [(Sonora $63 \times$ IRN 216-63) x Sonora 63], mostra um ciclo da emergência à maturação de 
112 dias, altura das plantas de $95 \mathrm{~cm}$, resistência a sete raças de ferrugem do colmo, elevada produtividade em condiçōes de irrigação por aspersão e moderada tolerância ao $\mathrm{Al}^{3+}$.

IAC-37 - Obtida por seleção de progênies, a partir do híbrido 1003 (Pel 4178-67 x S-12), destaca-se quanto à produtividade e a elevada tolerância à toxicidade de $\mathrm{Al}^{3+}$. Apresenta porte de $102 \mathrm{~cm}$, ciclo da emergência à maturação de 112 dias e moderada resistência às ferrugens do colmo e da folha.

IAC-46 - Originária do hibrido $F_{1} 687$ (IRN 597-70 x IAC-5), possui ciclo da emergência à maturação de 120 dias, altura das plantas de $84 \mathrm{~cm}$, grande resistência à ferrugem do colmo em condições de campo, boa produtividade $\mathrm{e}$ elevada tolerância à toxicidade de $\mathrm{Al}^{3+}$.

IAC-57 - Selecionada a partir do híbrido 1196 (IAC-5 x IRN 33-70), apresenta boa produtividade, moderada resistência à ferrugem do colmo, altura das plantas de $71 \mathrm{~cm}$, ciclo da emergência ao florescimento de 111 dias e moderada tolerância ao $\mathrm{Al}^{3+}$.

IAC-60 - Também obtida por seleção do híbrido 1196, tem mostrado elevadas produçōes em condição de irrigação por aspersão, resistência ao acamamento, porte semi-anão, $83 \mathrm{~cm}$, alta tolerância à toxicidade de $\mathrm{Al}^{3+}$, ciclo da emergência à maturação de 114 dias e grande resistência às raças prevalentes do agente causal da ferrugem do colmo.

IAC-22 - Obtida por seleção do híbrido 732 (Pel 21414-66 x IAC-5). Dadas as suas qualidades, tais como menores niveis de infecção de ferrugem do colmo, maior produtividade que os cultivares comerciais BH-1146 e IAC-5, foi lançada para cultivo comercial em 1983.

Os cultivares comerciais IAG-18 e Alondra-S-46, bem como uma amostra de trigo importado de procedência norte-americana obtida em moinho comercial, foram usados como controle.

\subsection{Análises químicas das farinhas}

Efetuaram-se as análises químicas das farinhas após a moagem do trigo em moinho experimental Brabender, modelo Senior, passando o material pelas unidades de quebra e redução.

Utilizaram-se os métodos da AMERICAN ASSOCIATION OF CEREAL CHEMISTS (AACC) (1974) $n=46-13$ (proteinas), $n^{\circ}$ 08-01 (cinzas), $n^{\circ}$ 32-15 (fibra), $n=44-15$ (umidade) e $n^{\circ}$ 30-20 (lipídios). Calculou-se o teor de carboidrato por diferença.

\subsection{Propriedades viscoamilográficas}

A determinação da viscosidade foi feita com o viscoamilógrafo Brabender, segundo o método AACC nº 22-10. 
Foram utilizadas para interpretar os amilogramas (gråfico de viscosidade em unidades amilográficas $x$ teinpo em minutos) as seguintes medidas: (a) temperatura inicial de geiatinização; (b) temperatura de viscosidade máxima; (c) faixa de gelatinização e (d) viscosidade máxima.

\subsection{Propriedades farinográficas}

As propriedades de mistura foram determinadas no farinógrafo Brabender, de acordo com o método da AACC n 54-21.

As caracteristicas do farinograma analisadas foram as seguintes: (a) absorção de água; (b) tempo de chegada; (c) tempo de desenvolvimento da massa; (d) estabilidade; (e) tempo de saída; (f) índice de tolerância a mistura e ( $g$ ) tempo de quebra.

\subsection{Propriedades extensigráficas}

As propriedades de extensão da massa foram determinadas com o extensígrafo Brabender, de acordo com o método no 54-10 da AACC (1974). As características usadas para interpretar o extensigrama foram: (a) extensibilidade; (b) resistência a extensão; (c) resistência máxima; (d) número proporcional e (e) área.

\subsection{Testes de panificação}

A qualidade de panificação das farinhas foi determinada segundo o método EL-DASH (1976), onde a consistência da massa e a temperatura são controladas e a absorção de água e o tempo ótimo de desenvolvimento da massa podem ser determinados objetivamente.

Utilizou-se a seguinte formulação para produção de pão em formas: fermento biológico $3 \%$, sal $1,75 \%$, sacarose $5 \%$, gordura vegetal hidrogenada $3 \%$, vitamina C $90 \mathrm{ppm}$ e água aproximadamente $60 \%$.

Avaliou-se a qualidade do pão pelo volume especifico $\left(\mathrm{cm}^{3} / \mathrm{g} \times 3,33\right)$, características externas e internas, aroma e gosto.

Determinaram-se os volumes dos pães após resfriamento, pelo método de deslocamento de sementes, através de um recipiente de volume previamente estabelecido.

Para cada uma das características, atribuiu-se um valor máximo, 100 pontos: aroma (10 pontos), sabor (15 pontos); características externas: volume (20 pontos), cor da crosta ( 10 pontos), quebra (5 pontos) e simetria (5 pontos), e características internas: qualidade da crosta (5 pontos), cor do miolo (10 pontos), granulosidade (estrutura da célula do miolo) (10 pontos) e textura do mılo (10 pontos). 
Foi adotada a seguinte classificação da qualidade do pão em função do total de pontos:

\begin{tabular}{|c|c|}
\hline$<70 \ldots \ldots$ & Sofrivel \\
\hline $70-80 \ldots \ldots \ldots$ & Regular \\
\hline $80-90 \ldots$ & Boa \\
\hline$>90 \ldots \ldots \ldots \ldots \ldots \ldots \ldots$ & Muito boa \\
\hline
\end{tabular}

\section{RESULTADOS E DISCUSSÃO}

\subsection{Análises químicas das farinhas}

A composiçăo química das dez amostras de farinha de trigo em estudo encontra-se no quadro 1. Os valores de proteina encontrados nas farinhas das linhagens IAC-22, IAC-37 e IAC-41 foram maiores que os encontrados nas farinhas de trigo importado e nos cultivares Alondra-S-46 e IAC-18, tomados como comparação de qualidade. De modo geral, tais valores foram de médio a alto.

QUADRO 1. Teores de umidade e composição química em base seca das farinhas de trigo de sete novas linhagens em comparação com dois cultivares comerciais, Alondra- $\mathrm{S}-46$ e IAC-18, e uma amostra de farinha de trigo norte-americano

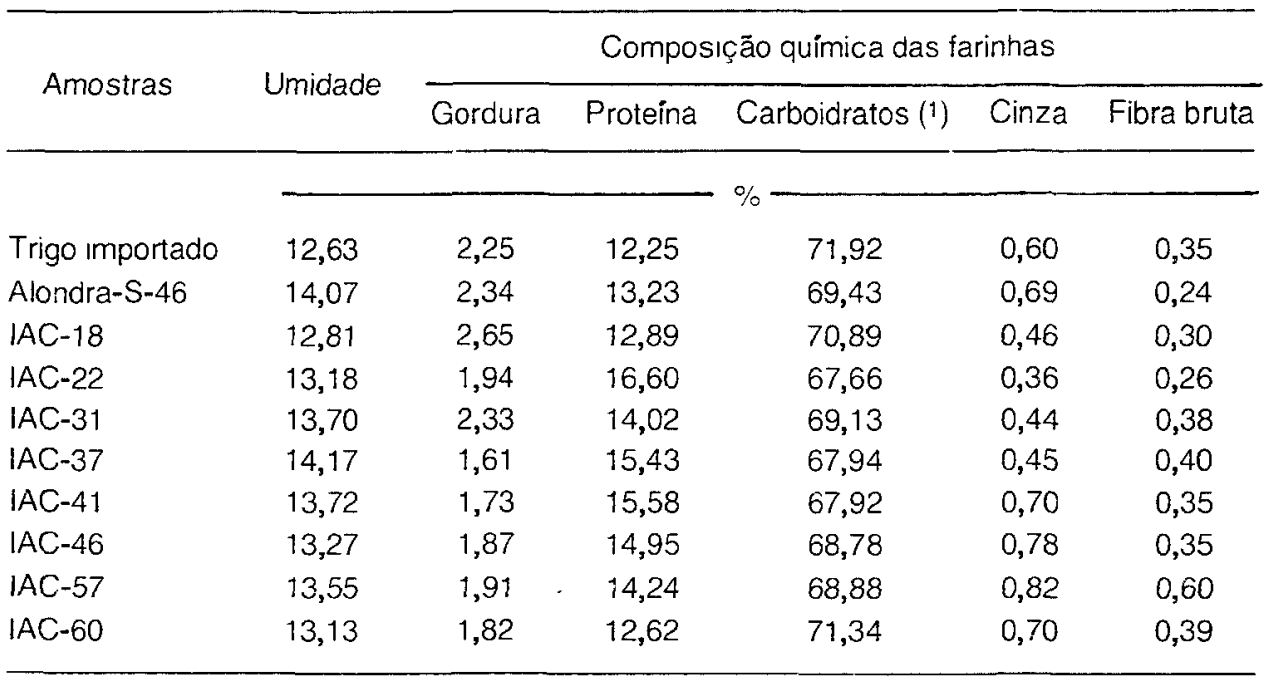

(1) Os teores de carboidratos foram calculados por diferença. 
Os resultados obtidos na análise de fibras das farinhas foram similares, exceto para a linhagem IAC-57, que apresentou um teor mais elevado, 0,60.

Em relação aos indices de cinza, as linhagens IAC-46 e IAC-57 apresentaram os valores mais altos, 0,78 e 0,82 respectivamente, em comparaçāo com as demais amostras analisadas.

\subsection{Características amilográficas das farinhas de trigo}

As medidas de viscosidade das misturas de farinha de trigo e água são utilizadas como um critério de qualidade de farinhas. Para uma análise mais extensiva das mudanças de viscosidade que ocorrem durante a formação da pasta, usou-se o viscoamilógrafo, que simula as condições que ocorrem no pão durante o seu cozimento.

O quadro 2 apresenta os valores da temperatura inicial de gelatinização, temperatura de viscosidade máxima, faixa de gelatinização e viscosidade máxima obtidos nos amilogramas das farinhas de trigo em estudo.

Quando uma suspensão de amido é aquecida, nem todos os grânulos começam a intumescer à mesma temperatura. Esse processo geralmente ocorre em uma faixa de temperatura chamada de faixa de gelatinização. Para o amido de trigo, esse intervalo varia de aproximadamente 52 a $63^{\circ} \mathrm{C}$.

Pelo quadro 2, pode-se observar que para todas as farinhas analisadas, as temperaturas iniciais de gelatinização foram em média $52^{\circ} \mathrm{C}$, exceto 'Alondra$-S-46^{\prime}$ e 'IAC-41' que tiveram 48,3 e $46,0^{\circ} \mathrm{C}$ respectivamente, mostrando que ambos têm grânulos de amido mais suscetiveis à hidratação a quente em relação aos demais. Isso pode ser interessante na produção de pão, visto que o amido hidratado (gelatinizado) é substrato para as enzimas amilolíticas que hidrolisam o amido gelatinizado a açúcares fermentáveis, durante o cozimento no forno.

A linhagem IAC-41 motrou a maior faixa de gelatinização, $23,3^{\circ} \mathrm{C}$.

Os dados de viscosidade máxima para todas as farinhas de trigo foram superiores a 1.000 unidades amilográficas (U.A.). Tais valores no viscoamilógrafo estão relacionados com o teor de alfa-amilase presente na farinha.

De acordo com PRATT (1971), o padrão de viscosidade máxima usado para controle de qualidade da farinha, no método comerciat de produção de pão, é de 475-625 U.A. para o pão tipo forma e de 400-600 U.A. para o tipo francês. indices inferiores indicam a presença de alto conteúdo de alfa-amilase, o que pode ser prejudicial à qualidade do pão (miolo gomoso e com grandes buracos, crosta muito escura). Por outro lado, valores de viscosidade acima de 1.000 U.A. podem retardar o processo fermentativo da massa, devido à menor quantidade de açúcares disponiveis às leveduras, produzindo pães de menor volume, granulosidade de miolo muito fechada e crosta muito clara. 
QUADRO 2. Caracteristicas dos amilogramas das farinhas de trigo de sete linhagens em comparação com dois cultivares comerciais, Alondra-S-46 e IAC-18, e uma amostra de farinha de trigo norte-americano

\begin{tabular}{lcccc}
\hline Amostra & $\begin{array}{c}\text { Temperatura } \\
\text { inicial de } \\
\text { gelatinização }\end{array}$ & $\begin{array}{c}\text { Temperatura } \\
\text { de viscosidade } \\
\text { máxima }\end{array}$ & $\begin{array}{c}\text { Faixa de } \\
\text { gelatinização }\end{array}$ & $\begin{array}{c}\text { Viscosidade } \\
\text { máxima }\end{array}$ \\
\cline { 2 - 4 } Trigo importado & 52,8 & oC & 65,5 & U.A. (1) \\
Alondra-S-46 & 48,3 & 66,3 & 12,7 & $>1000$ \\
IAC-18 & 52,0 & 67,0 & 18,0 & $>1000$ \\
IAC-22 & 53,5 & 65,5 & 15,0 & $>1000$ \\
IAC-31 & 52,0 & 68,5 & 12,0 & $>1000$ \\
IAC-37 & 52,0 & 70,0 & 16,5 & $>1000$ \\
IAC-41 & 46,0 & 69,3 & 18,0 & $>1000$ \\
IAC-46 & 52,0 & 69,3 & 23,3 & $>1000$ \\
IAC-57 & 53,5 & 68,5 & 17,3 & $>1000$ \\
IAC-60 & 51,3 & 67,8 & 15,0 & $>1000$ \\
\hline
\end{tabular}

(1) U.A. = Unidades amilográficas.

\subsection{Características farinográficas das farinhas de trigo}

As características farinográficas das farinhas de trigo das amostras estudadas acham-se no quadro 3.

A absorção de água da farinha, característica do cultivar de trigo, é de fundamental importância na qualidade dos produtos da panificação. Em geral, é desejável alta absorção, visto que ela leva a um maior rendimento. Em panificação, a absorção de água deve ser ajustada a um nivel ótimo para dar uma consistência da massa de 500 unidades farinográficas (U.F.) que é capaz de reter adequadamente os gases liberados na fermentação e no cozimento no forno.

Conforme o quadro 3 , entre as amostras de trigo analisadas, o trigo importado, o cultivar Alondra e as linhagens IAC-41 e IAC-46 tiveram os valores mais altos de absorção de água, superiores a 60\%. Segundo PRATT (1971), a absorção de água é influenciada por vários fatores, dentre os quais o teor de proteína e amido, características essas de cada cultivar de trigo. A absorçāo de água depende também do grau de extração da farinha e do teor de amido danificado no processo de moagem.

A interpretação do farinograma permite caracterizar as propriedades de mistura da massa. As principais são: tempo de chegada, tempo de desenvolvimento, estabilidade, tempo de queda e índice de tolerância. 
QUADRO 3. Caracteristicas farinográficas das farininas de trigo de sete linhagens em comparação com dois cultivares comerciais, Alondra-S-46 e IAC-18, e uma amostra de trigo

\begin{tabular}{|c|c|c|c|c|c|c|c|}
\hline Amostras & $\begin{array}{l}\text { Tempo de } \\
\text { chegada }\end{array}$ & $\begin{array}{c}\text { Tempo de } \\
\text { desenvolvimento } \\
\text { da massa }\end{array}$ & Estabilidade & $\begin{array}{l}\text { Tempo de } \\
\text { saída }\end{array}$ & $\begin{array}{c}\text { Tempo de } \\
\text { queda }\end{array}$ & $\begin{array}{l}\text { Indice de } \\
\text { tolerância }\end{array}$ & $\begin{array}{l}\text { Absorção } \\
\text { de água }\end{array}$ \\
\hline & & & $\min$ & 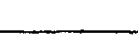 & - & U.F. (1) & $\%$ \\
\hline Trigo importado & 1,5 & 8,0 & 12,0 & 13,5 & 14,0 & 25 & 63,2 \\
\hline Alondra-S-46 & 2,5 & 5,5 & 6,5 & 9,0 & 9,0 & 60 & 61,6 \\
\hline IAC- 18 & 2,5 & 3,0 & 3,0 & 5,5 & 5,5 & 120 & 58,9 \\
\hline IAC-22 & 3,5 & 5,0 & 4,0 & 7,5 & 7,5 & 90 & 57,4 \\
\hline$|A C-3|$ & 1,0 & 5,0 & 12,0 & 13,5 & 11,5 & 30 & 53,5 \\
\hline IAC-37 & 3,0 & 5,0 & 4,5 & 7,5 & 7,5 & 70 & 59,2 \\
\hline IAC-4t & 2,5 & 8,0 & 13,5 & 16,0 & 16,0 & 20 & 61,0 \\
\hline IAC-46 & 2,5 & 6,0 & 7,0 & 9,5 & 9,0 & 60 & 60,7 \\
\hline IAC-57 & 1,5 & 5,5 & 10,0 & 11,5 & 10,5 & 50 & 55,3 \\
\hline IAC-60 & 1,0 & 3,5 & 7,0 & 8,0 & 8,0 & 60 & 53,4 \\
\hline
\end{tabular}

(1) U.F. = Unidades farinográficas.

O tempo de chegada é uma medida da velocidade de absorção de água pela farinha e corresponde ao tempo, em minutos, necessário para que a linha superior do gráfico atinja a linha das 500 U.F., após o início da mistura e da adição de água. $O$ tempo de chegada depende principalmente da quantidade e da qualidade da proteína e também da granulosidade da farinha (BLOKSMA, 1971).

Os menores valores do tempo de chegada foram observados para as linhagens IAC-31, IAC-57 e IAC-60 e para o trigo importado, embora todos os resultados se encontrem dentro de uma faixa normal para a farinha de trigo.

O tempo de desenvolvimento máximo da massa (TDMM) é uma indicação do ponto ótimo de energia necessária para o desenvolvimento mecânico da massa: é o tempo em minutos que ela leva para atingir o ponto máximo da curva. Pelo quadro 3 as farinhas de trigo importado e da linhagem IAC-41 tiveram valores de TDMM bem attos: 8,0; isso indica que essäs farin̄hās exigiam maior energia de mistura para desenvolver a estrutura da rede de glúten e que são provavelmente de boa qualidade tecnológica. Entretanto, as farinhas de 'IAC-18' e da linhagem IAC-60 apresentaram um tempo de desenvolvimento da massa bem baixo, 3,0 e 3,5 minutos respectivamente, mostrando possivelmente um glúten de baixa qualidade tecnológica.

O tempo de saída é uma característica farinográfica: indica que, depois dele, a massa não deverá mais ser misturada. É o tempo, em minutos, obtido 
desde o início do teste até a saída do gráfico da linha de 500 U.F. As linhagens IAC-41 e IAC-31 e o trigo importado tiveram os tempos de saída altos em relação às demais amostras, o que é característico de farinhas de trigo de boa qualidade.

A estabilidade à mistura da massa é uma indicação da qualidade da farinha, estando relacionada com a qualidade da proteina: é obtida pela diferença entre o tempo de saida e o tempo de chegada. As linhagens IAC-41 e IAC-31 e o trigo importado apresentaram grande estabilidade à mistura, enquanto o cultivar IAC-18 e as linhagens IAC-22 e IAC-37 mostraram-se fracas à mistura, o que é característico de farinhas fracas.

O indice de tolerância da massa à mistura é também um parâmetro indicativo da força do glúten da farinha. É a diferença em unidades farinográficas entre o topo da curva no ponto de desenvolvimento máximo da massa e o topo da curva medido cinco minutos após esse desenvolvimento ser alcançado. Dessa forma, confirmando os resultados obtidos anteriormente em relação às outras caracteristicas farinográficas, as linhagens IAC-41 e IAC-31 e o trigo importado exibiram os menores índices de tolerância, indicação de farinhas com glúten mais forte e adequadas à panificação.

A queda é o tempo, em minutos, desde o início da mistura até que o centro da curva atinja a linha de 470 U.F. As linhagens IAC-41 e IAC-31 e o trigo importado apresentaram os maiores tempos, confirmando, mais uma vez, as melhores caracteristicas do glúten e a melhor qualidade das suas farinhas.

\subsection{Características extensigráficas das farinhas de trigo}

Pelas características extensigráficas das farinhas - Quadro 4 - observa-se que as linhagens IAC-41, IAC-31 e IAC-57 mostraram os valores do número proporcional (resistência à extensão/extensibilidade) e da energia (área da curva) nas faixas normalmente encontradas para as farinhas de força média a forte. Isso significa que, do ponto de vista das características extensigráficas, essas farinhas apresentaram glúten com características adequadas para a produçäo de pão de boa qualidade.

O 'IAC-18' apresentou a relação entre resistência à extensão e extensibilidade muito baixa $(0,71)$. Além disso, seus baixos valores da resistência máxima e da área revelaram uma farinha de trigo com glúten fraco; portanto, com características panificáveis não adequadas.

As demais linhagens apresentaram características extensigráficas dentro da faixa classificada para as farinhas média a fraca.

\subsection{Avaliação da qualidade de panificação}

Pela avaliação da qualidade das farinhas na produção de pão, feita através do teste de panificação - Quadro 5 - pode-se observar que os maiores 
volumes específicos foram obtidos nos pães feitos com as farinhas de trigo americano e do cultivar Alondra-S-46, tomadas como base de qualidade para comparação, com os valores de 15,9 e 15,1 respectivamente. As linhagens IAC-31, IAC41, IAC-57 e IAC-37 apresentaram também altos valores de volume específico, apenas um pouco inferiores ao padrão. O volume é a característica de maior importância na avaliação da qualidade do pão, por ser afetado principalmente pela qualidade da farinha.

QUADRO 4. Características dos extensigramas das farinhas de trigo de sete linhagens em comparação com dois cultivares comerciais, Alondra-S-46 e IAC-18, e uma amostra de trigo norte-americano

\begin{tabular}{|c|c|c|c|c|c|c|}
\hline Amostras & $\begin{array}{l}\text { Tempo de } \\
\text { descanso }\end{array}$ & $\begin{array}{l}\text { Resistência à } \\
\text { extensāo (R) }\end{array}$ & $\begin{array}{l}\text { Resistência } \\
\text { máxıma (RM) }\end{array}$ & $\begin{array}{c}\text { Extensi- } \\
\text { bilidade (E) }\end{array}$ & $\begin{array}{c}\text { Número } \\
\text { proporcional } \\
(D=R / E)\end{array}$ & Área \\
\hline & $\min$ & U.E. (1) & U.E. (1) & $\min$ & $n^{0}$ & $\mathrm{~cm}^{2}$ \\
\hline \multirow[t]{2}{*}{ Trigo importado } & 45 & 320 & 490 & 195 & 1,64 & \multirow{2}{*}{109,9} \\
\hline & 90 & 300 & 520 & 180 & 1,66 & \\
\hline \multirow[t]{2}{*}{ Alondra-S-46 } & 45 & 250 & 360 & 180 & 1,38 & \multirow{2}{*}{91,2} \\
\hline & 90 & 250 & 350 & 200 & 1,25 & \\
\hline \multirow[t]{2}{*}{ IAC-18 } & 45 & 160 & 160 & 225 & 0,71 & \multirow{2}{*}{33,3} \\
\hline & 90 & 150 & 160 & 205 & 0,73 & \\
\hline \multirow[t]{2}{*}{ IAC-22 } & 45 & 140 & 310 & 235 & 0,59 & \multirow{2}{*}{102,8} \\
\hline & 90 & 180 & 320 & 235 & 0,77 & \\
\hline \multirow[t]{2}{*}{ IAC-31 } & 45 & 350 & 640 & 200 & 1,75 & \multirow{2}{*}{161,8} \\
\hline & 90 & 380 & 670 & 185 & 2,00 & \\
\hline \multirow[t]{2}{*}{ IAC-37 } & 45 & 230 & 350 & 210 & 1,09 & \multirow{2}{*}{91,8} \\
\hline & 90 & 230 & 390 & 200 & 1,15 & \\
\hline \multirow[t]{2}{*}{ IAC-41 } & 45 & 240 & 500 & 255 & 0,94 & \multirow{2}{*}{188,9} \\
\hline & 90 & 260 & 600 & 240 & 1,08 & \\
\hline \multirow[t]{2}{*}{ IAC-46 } & 45 & 210 & 420 & 225 & 1,15 & \multirow{2}{*}{140,2} \\
\hline & 90 & 260 & 490 & 215 & 0,97 & \\
\hline \multirow[t]{2}{*}{ IAC-57 } & 45 & 270 & 510 & 220 & 1,20 & \multirow{2}{*}{162,3} \\
\hline & 90 & 300 & 560 & 220 & 1,36 & \\
\hline \multirow[t]{2}{*}{$\mid A C-60$} & 45 & 260 & 440 & 195 & 1,33 & \multirow{2}{*}{103,1} \\
\hline & 90 & 230 & 460 & 180 & 1,28 & \\
\hline
\end{tabular}

(1) U.E. = Unidades extensigráficas. 
QUADRO 5. Avaliação da qualidade dos pães feltos com as farinhas de trigo de sete linhagens em comparação com dois cultivares comerciais, Alondra-S-46 e IAC-18, e uma amostra de trigo norte-americano

\begin{tabular}{|c|c|c|c|c|c|c|c|c|c|c|c|}
\hline \multirow[b]{2}{*}{ Amostras } & \multicolumn{4}{|c|}{ Caracteristicas externas } & \multicolumn{4}{|c|}{ Características internas } & \multirow[b]{2}{*}{ Aroma } & \multirow[b]{2}{*}{ Gosto } & \multirow[b]{2}{*}{$\begin{array}{c}\text { Contager } \\
\text { total }\end{array}$} \\
\hline & $\begin{array}{l}\text { Volume } \\
\text { especffico }\end{array}$ & $\begin{array}{l}\text { Corda } \\
\text { crosta }\end{array}$ & Quebra & Simetria & $\begin{array}{l}\text { Qualidade } \\
\text { da crosta }\end{array}$ & $\begin{array}{l}\text { Cor do } \\
\text { mıolo }\end{array}$ & $\begin{array}{l}\text { Estrutura } \\
\text { da célula } \\
\text { do miolo }\end{array}$ & $\begin{array}{l}\text { Textura } \\
\text { co miolo }\end{array}$ & & & \\
\hline & $\mathrm{cm}^{3} / \mathrm{g} \times 3,33$ & & & & & & & & & & \\
\hline Trıgo importado & 15,9 & 9,0 & 5,0 & 5,0 & 4,0 & 9.0 & 10,0 & 9,0 & 10,0 & 15,0 & 91,9 \\
\hline Alondra-S-46 & 15,1 & 8,0 & 3,0 & 4,0 & 4,0 & 9,0 & 8,0 & 8,0 & 10,0 & 15,0 & 84,1 \\
\hline LAC-18 & 14,1 & 7,0 & 3,0 & 2,0 & 3,0 & 7,0 & 7,0 & 7,0 & 10,0 & 15,0 & 75,1 \\
\hline $1 \mathrm{AC}-22$ & 12,4 & 7.0 & 3,0 & 2,0 & 4,0 & 9,0 & 8,5 & 8,0 & 10,0 & 15,0 & 78,9 \\
\hline $1 A C-31$ & 14,9 & 8,0 & 4,0 & 4,0 & 5,0 & 10,0 & 10,0 & 9,0 & 10,0 & 15,0 & 89,9 \\
\hline $1 A C-37$ & 14,0 & 7,5 & 3,0 & 4,0 & 4,0 & 8,0 & 8,0 & 7,0 & 10,0 & 15,0 & 80,5 \\
\hline LAC-41 & 94,8 & 10,0 & 5,0 & 5,0 & 5,0 & 10,0 & 10,0 & 10,0 & 10,0 & 15,0 & 94,8 \\
\hline LAC 46 & 13,3 & 7,0 & 3,0 & 4,0 & 3,0 & 8,0 & 8,0 & 6,0 & 10,0 & 15,0 & 77,3 \\
\hline$\angle A C-57$ & 14,7 & 7,0 & 3,0 & 4,0 & 4,0 & 8,0 & 8.0 & 8,0 & 10,0 & 15,0 & 81,7 \\
\hline LAC- 60 & 13,1 & 7,0 & 3,0 & 4,0 & 4,0 & 8,0 & 8,0 & 8,0 & 10,0 & 15,0 & 80,1 \\
\hline Valor máxirno & 20,0 & 10,0 & 5,0 & 5,0 & 5,0 & 10.0 & 10,0 & 10,0 & 10,0 & 15,0 & 100,0 \\
\hline
\end{tabular}

Foi atribuido, tanto ao aroma como ao gosto, o número máximo de pontos, visto que essas duas características são normalmente afetadas quando se adicionam sucedâneos da farinha de trigo e/ou novos ingredientes na formulação do pão.

As linhager.s IAC-41 e IAC-31 mostraram uma contagem total de pontos superior ou equivalente a 90: foram, portanto, classificadas como produtoras de pão de qualidade "muito boa", semelhante àquela obtida pelo trigo importado; IAC-57, IAC-37 e IAC-60, pão de qualidade "boa" e similar à do Alondra-S-46; as linhagens IAC-46 e IAC-22 tiveram o pior comportamento em relação à qualidade do pão, "regular", similar à do 'IAC-18'.

\section{CONCLUSÕES}

1) Os teores de proteina encontrados nas linhagens IAC-37 e IAC-41 e no cultivar $\mid A C-22$ foram maiores que os encontrados nas farinhas de trigo importado, 'Alondra-S-46' e. 'IAC-18', tomadas como controle de comparação de qualidade.

2) As farinhas de trigo analisadas tiveram viscosidade máxima superior a 1.000 unidades amilográficas, o que indica a ausência da enzima alfa-amilase. 
3) As farinhas de trigo importado e das linhagens IAC-31 e IAC-41 apresentaram características típicas de farinha de força média a forte, enquanto o cultivar IAC-18 e a linhagem IAC-60 mostraram caracteristicas de farinha de força média a fraca.

4) Os resultados das análises extensigráficas mostraram que as linhagens IAC-41, IAC-31, IAC-57 e IAC-46 apresentaram glúten com caracteristicas viscoelásticas adequadas para a produção de pão. $\mathrm{O}$ 'IAC-18' revelou características de glúten fraco e elasticidade e extensibilidade inadequadas para panificação.

5) Pela avaliação final da qualidade do pão pelo teste de panificação, conclui-se que:

a) As linhagens IAC-41 e IAC-31 foram classificadas como produtoras de pão de qualidade "muito boa", semelhante à da farinha de trigo importado.

b) As linhagens IAC-57, IAC-37 e IAC-60 produziram pão de qualidade "boa", semelhante à do cultivar Alondra-S-46.

c) A linhagem IAC-46 e o cultivar IAC-22 tiveram a pior performance em relação à qualidade do pão, "regular", semelhante à do 'IAC-18', também usado como comparação de qualidade por ser um cultivar de trigo nacional.

\section{SUMMARY}

\section{TECHNOLOGICAL EVALUATION OF NEW LINES OF WHEAT}

The new wheat lines IAC-22, IAC-31, IAC-37, IAC-41, IAC-46, IAC-57 and IAC-60, obtained from the Wheat Breeding Program of the Instituto Agronômico of the State of São Paulo, Brazil, were submitted to technological tests to evaluate the flour quality. Samples of wheat from the United States and of the wheat cultivars Alondra-S-46 and IAC-18 were used as controls. The wheat flours were submitted to chemical tests to determine the protein, lipid, ash, fiber and carbohidrate composition and to rheologic tests using a farinograph, an extensigraph and a viscoamilograph. The final quality of the wheat flour was evaluated through the bread test. The imported wheat, Alondra-S-46 and IAC-60 showed mill yields slightly superior to the other samples studied. The highest protein levels were found in the lines IAC-22, IAC-37 and IAC-41. These were superior to the levels found for the imported wheat sample, 'Alondra-S-46' and 'IAC-18'. All wheat flours exhibited maximum viscosity above 1,000 Amylograph Unities, indicating absence of the alfa amylase enzyme. The imported wheat and the lines IAC-31 and IAC-41 showed farinographic characteristics typical of medium to strong flour, while 'IAC-18' and IAC-60 of medium to weak flour. The extensigraphs showed that IAC-41, IAC-31, IAC-57 and IAC-46 presented gluten with adequate viscoelasticity characteristics for bread production. The bread tests allowed to conclude that IAC-41 and IAC-31 gave a "very good" quality bread, similar to the 
imported wheat; IAC-57, IAC-37 and IAC-60 yielded a "good" quality bread, similar to the "Alondra-S-46"; and IAC-46 and IAC-22 gave a "regular" quality bread, similar to the 'IAC-18'.

Index terms: wheat lines and cultivars; chemical tests, technological quality, rheologic tests, bread tests, protein level, maximum viscosity, farinograph characteristics.

\section{REFERÊNCIAS BIBLIOGRÁFICAS}

AMERICAN ASSOCIATION OF CEREAL CHEMISTS. Approved methods of AACC. Saint Paul, Minnesota, 1974.

BLOKSMA, A.H. Rheology and chemistry of dough. In: POMERANS, Y. Wheat Chemistry and Technology. Saint Paul, Minnesota, AACC, 1971. p.523-568.

CAMARGO, C.E.O. Estudos de variedades de trigo para o Estado de São Paulo. Piracicaba, Escola Superior de Agricultura "Luiz de Queiroz", 1972. 102p. Tese (Doutoramento)

; FELICIO, J.C.; BARROS, B.C.; FREITAS, J.C.; FERREIRA FILHO, A.W.P. \& CASTRO, J.L. Melhoramento do trigo: novas linhagens para o Estado de São Paulo. Arquivos do Instituto Biológico, São Paulo, 52(1/4):27-37, 1985a.

- - - FREITAS, J.G.; BARROS, B.C.; CASTRO, J.L. \& SABINO, J.C. Melhoramento do trigo. XII. Comportamento de novas linhagens e cultivares no Estado de Sāo Paulo. Bragantia, Campinas, 44(2):664-685, $1985 \mathrm{~b}$.

\& OLIVEIRA, O.F. Tolerância de cultivares de trigo a diferentes niveis de aluminio em solução nutritiva e no solo. Bragantia, Campinas, 40:21-31, 1981.

EL-DASH, A.A. An objective experimental baking test using the farinograph and extensigraph. In: AMERICAN ASSOCIATION OF CEREAL CHEMISTS. Annual Meeting, 61., New Orleans, 1976.

FELICIO, J.C.; BARROS, B.C.; CAMARGO, C.E.O. \& BÄR, W.H. Maracal (IAC-17) e Xavantes (IAC-18): novos cultivares de trigo para o Estado de São Paulo. Bragantia, Campinas, 42:15-25, 1983.

- CAMARGO, C.E.O.; BARROS, B.C. \& VITTI, P. Iguaçu (IAC-21) e Araguaja (IAC-22): cultivares de trigo de sequeiro para o Estado de São Paulo. Bragantia, Campinas, 44(1):115-128, 1985.

PRATT JUNIOR, D.B. Criteria of flour quality. In: POMERANZ, Y. Wheat Chemistry and Technology. Saint Paul, Minnesota, AACC, 1971. p.201-226.

PROGNÓSTICO 84/85. São Paulo, Instituto de Economia Agrícola, v. 13, 1984. 